outbreak of infection at Stanley Royd's hospital in 1986.

There are several reasons why the responsibilities and roles of consultants should be reconsidered. Dr Muijen has written about some of them.

In recent months we have received many letters from members on aspects of these, e.g. on the distance from an acute or non-acute unit that medical staff can be resident, where medical responsibility lies for patients who are referred to or by non-medical colleagues, and perhaps most seriously, when is it appropriate for managers to decide which patients can be discharged so that an even more seriously ill patient can be admitted.

The report of the CMO's working group on specialisation indicates that postgraduate medical training should be structured, with a clear end-point. This implies that we know what we are training people to do. What is consultant work in psychiatry? Dr Muijen has challenged some aspects of Mental Health of the Nation and trainees have been telling us for years that training for work in "the community" is not our strong suit.

Mental Health of the Nation shows the levels of consultant manpower required to run an adequate service. But isn't further work required to examine the requirement for other grades of staff, both medical and non-medical? Such calculations can only be made when both the responsibilities and the numbers of consultants have been determined. While I agree with Dr Muijen that professional responsibilities must be discussed and identified in a multi-professional framework, and we maintain and try to improve our relationships with colleagues, there is an urgent need for us to clarify what our unique contribution to the psychiatric service is.

It has been agreed by the Executive and Finance Committee that I should chair a small working group which will produce a policy statement as quickly as possible setting out the core responsibilities of consultant psychiatrists and their role in the NHS. I hope that it will also be possible to produce additional information which is specifically relevant to each psychiatric specialty.

As Dr El-Komy says in his letter below, Council has recently produced a short statement on medical responsibility when a patient is referred by a nondoctor to a colleague who is also non-medical (Psychiatric Bulletin, April 1993, 17, 251). This did not extend to referrals made to non-medical members of the multidisciplinary team by general practitioners, and should be.

I hope that most members of the College agree with Dr Muijen that "consultant psychiatrists, often represented by the Royal College of Psychiatrists, should take an active part in developments, and should be recognised as representing the best interest of the consumers i.e. their patients".
There is much concern in the public arena at the time of writing about standards of practice in medicine and we are developing a vigorous programme of continuing medical education in psychiatry.

I hope that this piece of work which we are now embarking on will facilitate even higher standards of care for psychiatric patients being delivered than at present, and that members and fellows will write to me with their views in order that the working group can be as well informed as possible. It will not surprise readers to learn that colleagues at the Department of Health are interested that we are embarking on this and wish to see the outcome.

Fiona CaldicotT

President

\section{Medical responsibility in the case of patients referred to non medical staff of a mental health unit or trust directly from non-medical services}

\section{DEAR SIRS}

I read with interest the long overdue statement by the Royal College of Psychiatrists regarding medical responsibility (Psychiatric Bulletin, April 1993, 17, 251). This issue has been a matter of concern among the consultant and medical staff in the West Dorset Mental Health NHS Trust. However, the statement has not clarified an important matter relating to referrals made by general practitioners to individual members of the mental health team, who may have no previous knowledge of the patient and bypassing the appropriate consultant. Some members of the team are working more or less independently to provide a specialised service, e.g. psychodrama, behavioural cognitive therapy etc., and it might be asked whether a particular member will be the most suitable person to deal with a patient with a psychiatric illness in need of a different treatment approach.

I think further clarification is needed of this important issue which I believe poses a problem not only in West Dorset but in other districts.

Forston Clinic

A. EL-KomY

Herrison

Dorchester, Dorset

DT2 9TV

\section{Problems of the special hospitals}

DeAR Sirs

I welcome the interest shown in the future of Ashworth Hospital by Dr C. M. Green (Psychiatric Bulletin, April 1993, 17, 243). As there has been no response from your other readers to the report of 
the Committee of Inquiry into complaints about Ashworth Hospital, my views may help initiate debate on measures needed to rectify the abuses identified in the report. However, I would add that my contacts with the hospital were from 1977 to 1986, when it was known as Moss Side Hospital, when I furnished over 50 independent psychiatric reports to the Mental Health Review Tribunal.

I was horrified by the intimidating atmosphere, the rule of thumb diagnoses, the punishment of patients for applying to the Tribunal, the victimisation of the very few nurses who tried to form therapeutic relationships with patients and the lack of treatment other than medication. Patients very seldom went on leave and then it was escorted. There were no rehabilitation facilities. The vast majority of the patients whom I saw were inadequate personalities who had never been dangerously violent and in the hospital for over seven years for minor offences. In several cases, it was as a result of television programmes that they were discharged.

In my opinion Ashworth Hospital, and other Special Hospitals, are irreformable and should be closed. The small number of really dangerous patients should be treated in small units, run on therapeutic community lines, with a high staff patient ratio and specially trained staff. The remainder should be assessed by experts from outside the institution. It will be found that many are suitable for sheltered villages on the lines of the Camphill villages. Others could be treated at the Henderson Hospital.

18 Fontenoy Street

MAIRE O'SHEA

Dublin 7, Ireland

\section{DeAR SIRS}

Dr Maire O'Shea has expressed her strongly worded concerns about the special hospitals and remarks that no other readers of the Bulletin have as yet responded to the content of the report of the Committee of Inquiry into complaints about Ashworth Hospital.

In fact the Forensic Section and the Council of the College has in recent months made several responses but perhaps these need to be more widely publicised.

At the President's request, Professor Arthur Crisp convened a group which has provided a detailed commentary on the implications of the report, with special attention to the duties and responsibilities of psychiatrists in Special Hospitals. The College had adopted as an official College report, a paper which was submitted to the Department of Health for consideration by the Reed Committee High Security Working Party. In that it does recommend inter alia that no consultant psychiatrist should have a case- load larger than 45 patients, that the special hospitals should be reduced in size and that the total number of places should be reduced from approximately 1,700 to 1,000 . The SHSA has repeatedly expressed its concern that many patients resident in special hospitals remain there unnecessarily and has urged local psychiatric services to remedy the situation which has many features in common with those in the Irish Republic. The vexed questions about whether personality disordered patients should be treated in hospital and, if so, by what means, has been considered by another Reed working party to which the College has contributed. One contribution was a most useful research paper from Dr Rosemarie Cope which clarified current opinion among forensic psychiatrists. Some shared the kind of therapeutic optimism which Dr O'Shea appears to have.

My own personal opinion is that all of us aware of the problems in special hospitals and who did so little to remedy them should pause before indulging in any ill-considered criticism of colleagues working in special hospitals who not only grapple with very difficult clinical problems but with institutional arrangements which are unhelpful.

James A. C. MacKeith Chairman, Forensic Section

\section{Co-ordination of exams}

DeAr SiRs

Talking to other trainees who recently sat the MRCPsych, I noticed that we all experienced a prolonged period of uncertainty during the exam and when awaiting the result. For Part II the time between sitting the written exam and receiving the result was eight weeks with three weeks between the written and clinical part.

Sitting an exam is unpleasant and causes anxiety and stress to the candidate. Not only are the candidates themselves affected, but also their ability to function at a normal level at work and to relate to colleagues and patients.

Due to the late notification of the exact date of the clinical exam, it is virtually impossible to give appointments to patients for three consecutive days, which can affect the service quite severely. I can see no reason for not having a date for the clinical exam from the outset, as proceeding to sit it does not depend on the result of the written papers.

Also, why is the wait for the result so long? The clinical exam is marked on the day and the MCQ papers marked by computer, leaving only the essay and short answer question paper to be marked by examiners.

Alder Hey Hospital

Brigitta C. Bende 